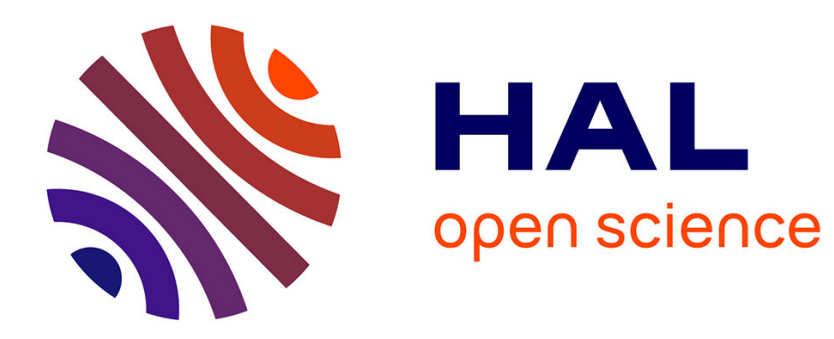

\title{
3D printing of earth-based materials Processing aspects
}

A. Perrot, Damien Rangeard, E. Courteille

\section{To cite this version:}

A. Perrot, Damien Rangeard, E. Courteille. 3D printing of earth-based materials Processing aspects. Construction and Building Materials, 2018, 172, pp.670-676. 10.1016/j.conbuildmat.2018.04.017. hal-01833252

\section{HAL Id: hal-01833252 \\ https://hal-univ-rennes1.archives-ouvertes.fr/hal-01833252}

Submitted on 13 Jul 2018

HAL is a multi-disciplinary open access archive for the deposit and dissemination of scientific research documents, whether they are published or not. The documents may come from teaching and research institutions in France or abroad, or from public or private research centers.
L'archive ouverte pluridisciplinaire HAL, est destinée au dépôt et à la diffusion de documents scientifiques de niveau recherche, publiés ou non, émanant des établissements d'enseignement et de recherche français ou étrangers, des laboratoires publics ou privés. 


\title{
3D Printing of earth-based materials: Processing aspects
}

\author{
A. Perrot ${ }^{1, *}$, D. Rangeard ${ }^{2}$, E. Courteille ${ }^{2}$ \\ *corresponding author \\ 1 Univ. Bretagne Sud, FRE CNRS 3744, IRDL, F-56100 Lorient, France \\ *arnaud.perrot@univ-ubs.fr \\ 2 INSA Rennes, EA 3913, LGCGM, F- 35000 Rennes, France
}

\begin{abstract}
Due to its low environmental impact, earth construction has received much consideration in recent years. Nevertheless, its development remains limited due to low production rate. Recent developments have been made to improve earth-based materials mixdesign and processing methods. Simultaneously, digitally based construction methods have been introduced in the field of construction especially for cement-based materials application. Among these new techniques, the so-called 3D printing by extrusion deposit has been the most intensively studied. In this study, we assess the possibility of adapting this technique to earth-based material. After making the earth’s rheological behaviour suitable for 3D printing, a laboratory-scale printing has been carried out and the printed samples have been mechanically tested.
\end{abstract}

Keywords: earth material, rheology, 3D printing, additive manufacturing 


\section{Introduction}

Earthen construction has recently regaining much attention in the building industry due to its low environmental impact and recyclability [1-4]. Nevertheless, the development of earthen construction is still limited because of the price, insurability difficulties and bad durability due to high water sensitivity. The high price is mostly due to the labour cost and to the time required for the material to harden and by a slower production rate than that of the concrete industry. At the present time, it is difficult to have a mix-design that allows for both fast casting and sufficient strength in the dry state. In order to address both problems and to improve mix-design of earth-based material, a recent trend has been to apply scientific knowledge and expertise developed by the concrete industry to earthen construction (Gnanli et al., 2014) [4, 6-8].

Some attention has been paid to the possibility of simulating the cement setting by using biopolymers such as alginate [9-11] or using a combination of hydraulic binders and admixtures [8, 12].

Moreover, unconventional processing methods have been recently introduced and studied to improve the simplicity of building with earth and accelerate the building rate. For example, extrusion [13, 14], self-compacting clays [15] or hyper compaction [16] have been developed for that purpose.

A recent trend in construction is to introduce digitally based construction method such as 3D printing in order to accelerate the production rate, improve the security of workers, and provide design freedom to architects. Cement-based materials 3D printing is beginning to be well documented [17-24]. Among the developed techniques, extrusion-based additive manufacturing methods have been the most studied [17-21]. In this technique, the successive layers of concrete are deposited by a robot to build a complete structure. It is important to 
note that the success of this process is based on a competition between the material structural build-up rate and the construction rate [21, 23]: the deposited material must be hard enough to support the increasing load induced by subsequently deposited layers of the "in process" construction. It follows that the fast development of so-called green strength of the cementbased material is required to ensure fast production and structure stability; this problem has required an accurate description of the evolution of the cement-based material with time [2528].

The basic aim of this paper is to show that it is possible to print a structure with an earthbased material. It is a great challenge to attempt to mix the world oldest construction material with the newest construction processing techniques. To achieve this objective, alginate seaweed biopolymer has been added to earth in order to provide fast development of the earth's green strength, such fast hardening is here studied and described. This method allows the computation of the maximum building rate of the structure. The elastic rigidity of the freshly mixed earth has also been evaluated using the penetration method. To our knowledge, it is a first study dealing with earth 3D printing, however some clay-based systems have already been printed at small-scale in the ceramics industry [29-32]. In this paper an example of laboratory-scale printing of an earth structure is presented and the subsequent mechanical testing of the final structures.

\section{Materials and methods}

\section{II.1 Materials}

The tested material was a raw earth coming from Saint-Sulpice-La-Forêt (Ille et Vilaine, France). It was a fine soil with a particle size distribution (PSD) showing 60\% particles finer than $10 \mu \mathrm{m}$; the $\mathrm{d}_{50}$ diameter was equal to $8 \mu \mathrm{m}$. The clay particles were a mixture of quartz, 
kaolinite, illite and smectite (these results were obtained by XRD analysis of the natural material, material after thermolysis at $550^{\circ} \mathrm{C}$, and material treated with etylen-glycol). The plasticity index of this soil was 21 with a liquid limit of $48 \%$ and a plastic limit of $27 \%$. The tested water content was $45 \%$. In order to assess the workability, the material yield stress was measured with a Anton Paar Rheolab QC device in a vane tests configuration (stress growth procedure at constant strain rate of $0.05 \mathrm{~s}^{-1}$, cup radius $50 \mathrm{~mm}$, vane diameter $11 \mathrm{~mm}$ and vane height of $40 \mathrm{~mm}$; see [33] for more details in the procedure). At such a low shear rate, viscosity effects are negligible and yield stress could be computed from the measured torque peak value at flow onset. The vane geometry used in this study consisted of four blades around a cylindrical shaft. The measured yield stress value is $1.5 \mathrm{kPa}$ which makes the material consistency close to the liquid state [34] which is expected to be helpful to ensure earth pumpability.

The raw earth used in the study has been used on cob construction site. A $1 \mathrm{~mm}$ mesh sieve has been used to remove the largest particles. The particles size distribution should not present too large particles (a typical ratio of pipe to maximum particles diameter should be around 10). Moreover, the amount of sand and gravel should be limited (less than 80 percent the random packing fraction [25]) in order to avoid frictional behaviour and to ensure pumpability. This is the case for the tested material.

A commercial alginate was used in this study. Alginate is a family of seaweed biopolymers which are alginic salts obtained from the cell walls of brown seaweed. The alginate used was a white powder of alginic salt Cimalgin HS3® supplied by Cimaprem (Redon, France). This product is designed to make high strength gel for arts and molding applications. The HS3 product was mostly composed of alginate salt with "on demand" calcium release agents that allowed the monitoring of the duration of alginate gel network creation. Alginate can form a cross-linked isotropic insoluble gel when a soluble form of alginate nucleates with divalent 
metal cations like $\mathrm{Ca}^{2+}$ that can be found in earth-based materials. Chains of alginate make junctions by intercalating divalent cations creating a sort of egg-box connection [35]. In order to improve the dispersion of alginate within the earth material, the HS3 powder was firstly mix with an equal mass of water.

Alginate is not the only possible admixture, cement or hydraulic binders can be also used to induce a fast structural build-up of earth.

The earth was prepared using high capacity Hobart mixer. Dry earth was first introduced into the bowl and water was then added, the quantity being that to attain a water content of $45 \%$. The mixing procedure consisted of a 4 minutes low velocity mixing stage, followed by a high velocity mixing stage of 5 minutes. Between these two stages, the bowl was scrapped in order to ensure that no unmixed material remained adhered to the bowl. Eight $8 \mathrm{~kg}$ batches of the mix of water and earth were prepared and put in a 100 liters container for 24 hours for homogenization.

The alginate solution was prepared just before the printing and was mixed with the wet earth (water content of 45\%) using a mortar hand mixer for 4 minutes.

The material composition was summarized in table 1.

Table 1: Materials mix design - component mass/earth mass ratio

\begin{tabular}{|l|l|l|l|}
\hline & Earth & Water & Cimalgin HS3 \\
\hline With Cimalgin & 1 & 0.45 & 0.03 \\
\hline Without Cimalgin & 1 & 0.45 & 0 \\
\hline
\end{tabular}

\section{II.2 3D Printer}


The 3D printer consisted of the combination of a 6-axis industrial robot designed by Staübli robotics (load capacity of $195 \mathrm{~kg}$ ) with a TP5 Giema electric pump designed for mortar/render application (maximum pressure of $20 \mathrm{bar}$, maximum flow rate of $40 \mathrm{l} / \mathrm{min}$ ).

The connection between the pump and the robot was made using a 13 metre, $35 \mathrm{~mm}$ diameter flexible pipe (Figure 1). Two extruder die geometries were tested. The first one is a die with $35 \mathrm{~mm}$ in diameter and of circular cross section and the second has a rectangular cross section of $21 \times 40 \mathrm{~mm}^{2}$. These configurations ensured that there was no sectional reduction in the earth's flow path. The printer was able to print a volume of around one cubic meter. The sections were also chosen to make the minimal flow rate of the pump adapted to the robot velocity. The layer height is also limited by the yield stress of the material in order to have single layer with no settlement.

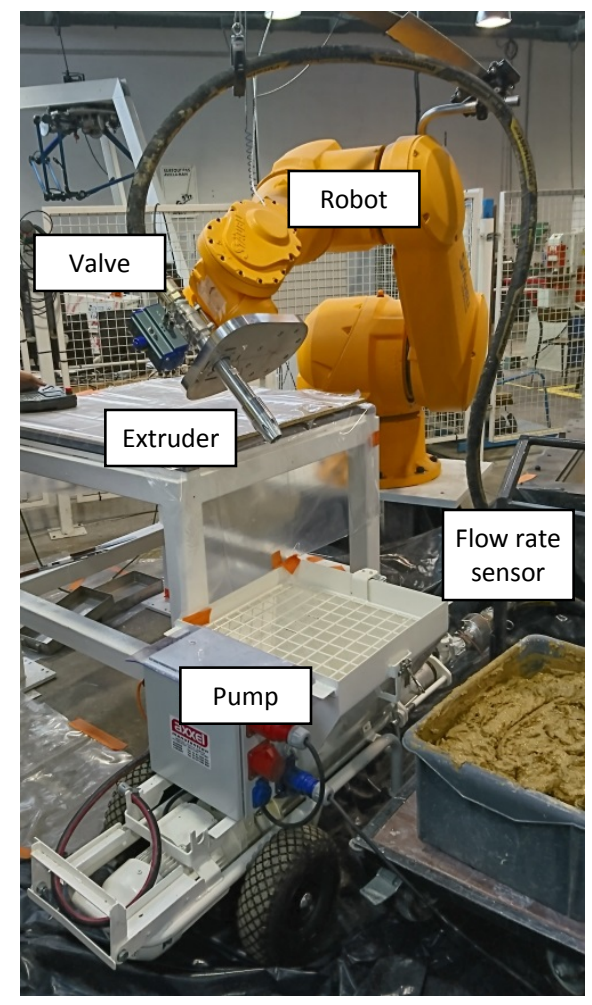

Figure 1: 3D printer for earth-based material 
A solenoid valve was added at the extruder die to stop the flow in the pipe when the pump motor was stopped. A flow rate sensor was added at the pump outlet to aid the control of the velocity of the robot head that held the extruder.

The robot was able to deposit layers of earth-based materials on a controlled path. The printing paths were designed to build samples consisting of 4 cylinders ( 2 layers of 2 side-byside cylinders) for the circular die and four superimposed layers for the rectangular die; these samples were used for subsequent mechanical testing (Figure 2). Once printed, the samples were kept at controlled room temperature $\left(20^{\circ} \mathrm{C}\right)$ and relative humidity (50\%).
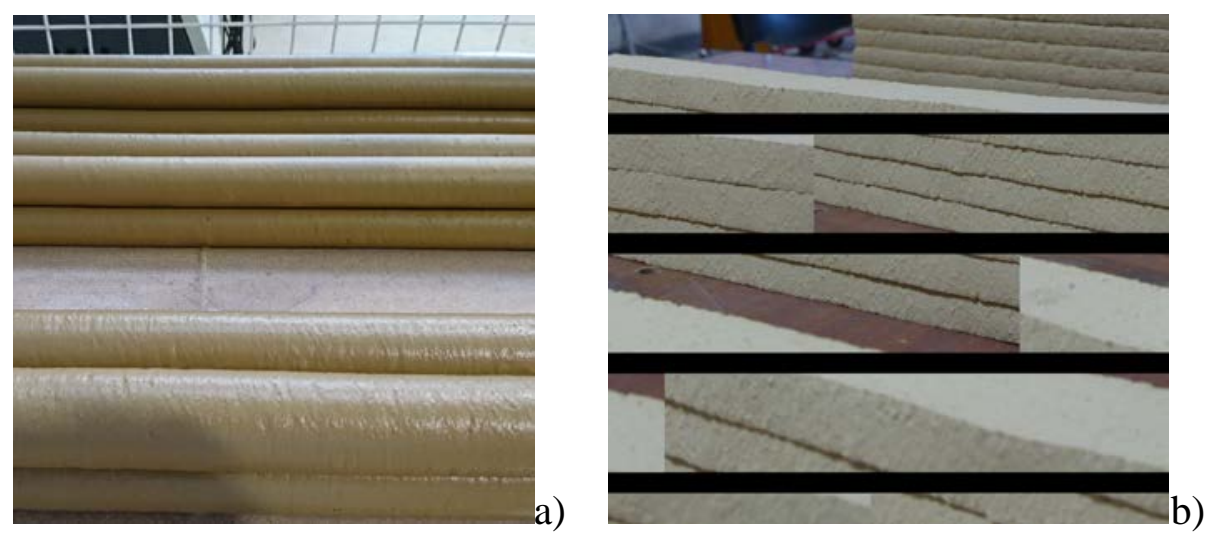

Figure 2: Printed samples for mechanical tests: a) printed with circular cross section - b) printed with rectangular cross section

\section{II.3 Green strength measurement}

In order to measure the green strength development of the material with time, a measurement system able to measure yield stress ranging from $1 \mathrm{kPa}$ to over $1 \mathrm{MPa}$ had to be designed. The penetration tests was a solution that has already been used to monitor the build-up and setting of cement paste, this test method was used in this study [26, 27].

The penetrometer used was cylindrical, $12 \mathrm{~mm}$ diameter and $20 \mathrm{~mm}$ high and the penetration force was recorded using a $50 \mathrm{~N}$ or $2 \mathrm{kN}$ sensor depending on the strength of the sample. 
Penetration was carried out to a maximum penetration depth of $10 \mathrm{~mm}$ at a constant penetration velocity of $1 \mathrm{~mm} / \mathrm{min}$.

The penetration resistance $F$ was assumed to be the combination of the bottom squeezing effect under the cylinder $F_{\text {bottom }}$ and the friction along the cylinder vertical surface $F_{\text {friction }}$ :

$$
F=F_{\text {friction }}+F_{\text {bottom }}
$$

It was assumed that during penetration, yield stress (shear yield stress at the vertical surface and elongational yield stress at the bottom) was reached. Equation (1) can be written as a function of the yield stress (assuming that the material follows a Von Mises plastic criterion):

$$
F=\frac{\sigma_{0} \pi D_{p e n} h_{p e n}}{\sqrt{3}}+\frac{\sigma_{0} \pi D_{p e n}{ }^{2}}{4}
$$

Where $\sigma_{0}$ is the elongational yield stress, $h_{p e n}$ is the penetration depth and $D_{p e n}$ is the diameter of the cylinder. The apparent elongational yield stress $\sigma_{0}$ is computed and is considered to be equal to the maximum value of the ratio of the recorded force over the contact surface between the earth and the cylinder:

$$
\sigma_{0}=\frac{F}{\pi\left(D_{p e n} h_{p e n} / \sqrt{3}+D_{p e n}^{2} / 4\right)}
$$

Penetration tests were carried out during the first seven days after the mixing of the material on samples with and without alginate.

An apparent elastic modulus was also computed, in this case, we considered that the applied vertical stress could be derived from the penetration force F:

$$
\sigma_{v}=\frac{4 F}{\pi D_{p e n}^{2}}
$$

Assuming linear elasticity of the material, and that the penetrometer is perfectly rigid in comparison with the material, the penetration depth $h_{p e n}$ is linked to the applied vertical stress by the following relationship [35] : 
$h_{p e n}=\frac{\pi\left(1-v^{2}\right)}{4 E D_{p e n}} \sigma_{v}$

An "elastic" modulus $E$ of the material can then be derived from the apparent applied vertical stress - penetration curve. The $E$ value was computed for a penetration depth of $1.2 \mathrm{~mm}$ (corresponding to a vertical deformation of the material about $10 \%$ ) and corresponds to a secant modulus.

\section{II.4 Compressive strength measurements}

Tests were carried out to check if the printed samples had sufficient and acceptable compressive strength. The compressive strength of cut samples $(70 \mathrm{~mm}$ high, $35 \mathrm{~mm}$ in width and $70 \mathrm{~mm}$ wide) was determined using a $50 \mathrm{kN}$ loading frame. The tests were carried out at a constant velocity of $1 \mathrm{~mm} / \mathrm{min}$.

An apparent compressive strength (Maximum recorded force over the section 70x35 mm²) was then computed.

\section{Optimizing rheological behaviour and fresh properties of earth for 3D printing}

Concrete or earth material 3D printing by extrusion is a multistep process where the material has to be firstly pumped before being extruded and deposited layer by layer. Once deposited, the material has to be firm enough to keep its shape and to sustain the weight of the layers placed above. The behavior of the freshly mixed earth-based material has to be well adapted for every steps and a mix-design window has to be found between fluidity for pumping and extrusion and strength for the form stability of the deposited layers. 
In this study, the pumping system had a maximum pressure of 20 bar and the length of the pipe was $13.3 \mathrm{~m}$ with an inner diameter of $35 \mathrm{~mm}$. Preliminary pumping tests have shown that the water content of the tested earth must be at least $40 \%$ to ensure that the pumping pressure remained under 20 bar. At such a water content, the shear yield stress of the material was equal to $2.2 \mathrm{kPa}$. To maintain a safety margin during the process, a water content of $45 \%$ was chosen for the 3D printing test. For such a water content, the shear yield stress of the material was equal to $1.5 \mathrm{kPa}$. It is worth noting that addition of alginate powder induced a thickening of the earth. However, in our study, dry alignate was firstly mixed with the same weight of water in order to improve the dispersion of the powder. This additional water used for dispersion also allowed the yield stress of the earth at $1.5 \mathrm{kPa}$ to be maintained. In our case, the extrusion step did not induce additional flow resistance because there was no reduction of the section at the die exit.

As for concrete 3D printing, the major constraint is due to the fact that the deposited layers of earth have to sustain their self weight and the weight of the subsequently deposited layers [21, 23]. This property, known as buidability in the literature [19], has recently been described as the competition between load increase due to the printing rate and the structural build-up of the material $[21,23]$. An analysis of this competition for concrete 3D printing allows the computation of the maximum printing rate and the minimal time between the deposits of two successive layers.

An illustration of this analysis is shown on Figure 3 where the evolution of the yield stress of earth at rest with and without alginate is plotted. The stress induced by the weight of 1 and 2 metre walls is also reported on this figure. We can see that the evolution of the earth's strength with time is highly non-linear. This figure shows the beneficial contribution of 
alginate in terms of fast structural build-up of the earth. It appears that the earth with alginate develops sufficient strength to sustain the weight of a $1 \mathrm{~m}$ wall in approximately 0.1 hour (6 minutes) while, without alginate, the time required for the earth to develop sufficient strength is more than 24 hours. Without alginate, the only mechanism that induces a strengthening of the earth is drying. Such a slow hardening mechanism is an order of magnitude longer than the expected construction rate and partly explained why earth construction is not widely used in industrial applications. Using an additional fast setting binder such as alginate allows a rapid development of the material's green strength that would allow a target of building an entire section of a building in a working day.

It is also interesting to note that the addition of alginate (with the additional water) only slightly affects the final strength of the material once the dry state is reached.

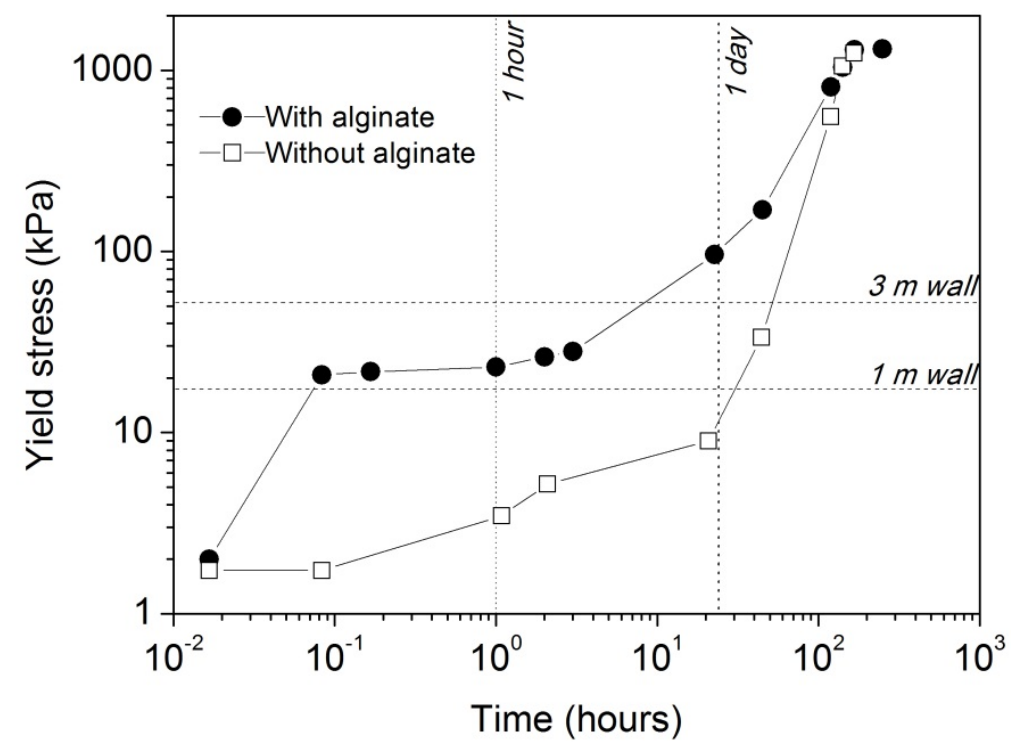

Figure 3: Evolution of the yield stress of the earth at rest with and without alginate.

As proposed by Wangler et al. [23], the vertical load of the printed structure induced a compressive stress that is equal to $\rho g H$ where $\rho$ is the density equal to $1750 \mathrm{~kg} / \mathrm{m}^{3}$ in the fresh state and $H$ is the height of the printed structure above a given layer, for example a 3 metres 
high wall induced a vertical stress equal to $52 \mathrm{kPa}$. Earth with alginate is able to sustain the weight of a vertical assembly of layers within 10 hours while without alginate, the time needed to have sufficient strength would be around 50 hours (more than 2 days). It is worth noting that $3 \mathrm{D}$ printing is not the only process able to build a 3 meters wall in a working day. Rammed earth is able to build structure as fast as 3D printing. However, 3D printing enables to work without formwork.

An additional factor concerns the adherence between layers; this issue may affect the maximum operating window between the deposit of two successive layer. Wangler et al. have proposed a criterion based on the competition between material shear strength and shearing induced by the deposition of a new layer [23], however this point has not been addressed in this study. It can be envisaged that additional techniques could be able to mechanically connect deposited layers using binders, nails or others types of solutions.

It is also important to estimate the elastic deformation of the first deposited layer during the printing. The evolutions of the measured apparent elastic moduli of the earth with and without alginate are plotted in Figure 4. The elastic moduli variations are very close those of yield stress. Alginate allows a faster increase in the material rigidity. For a building rate of 1 metre per day (24 hours), the elastic moduli of the earth with alginate is around $1 \mathrm{MPa}$ and the vertical stress is equal to $17 \mathrm{kPa}$. Therefore, the deformation of the first layer is equal to $1.7 \%$; this deformation is not negligible but its value remains limited. For a building rate of 3 meters per day (24 hours), the elastic moduli of the earth with alginate is around $1 \mathrm{MPa}$ and the vertical stress is equal to $52 \mathrm{kPa}$. Therefore, the deformation of the first layer is equal to $5.2 \%$. At such a rate, a correction of the printed height should be made in order to correct the elastic deformation effect. However, without alginate, at 24 hours, the elastic modulus is only around 
$100 \mathrm{kPa}$. In this case, for a one metre wall printed in 24 hours, the deformation of the first layer would be $17 \%$ and it even reaches $50 \%$ for a three meters high printed wall. Therefore, printing earth without alginate would be a very low process if the deformation of the layer is not allowed.

It is worth noting that the elastic modulus increase is important in order to avoid the collapse of the structure by buckling. As pointed out by Wolfs et al. for concrete, slender printed structure can collapse due to self-buckling [36]. This failure phenomenon is directly linked to the elastic modulus profile along the slender printed element.

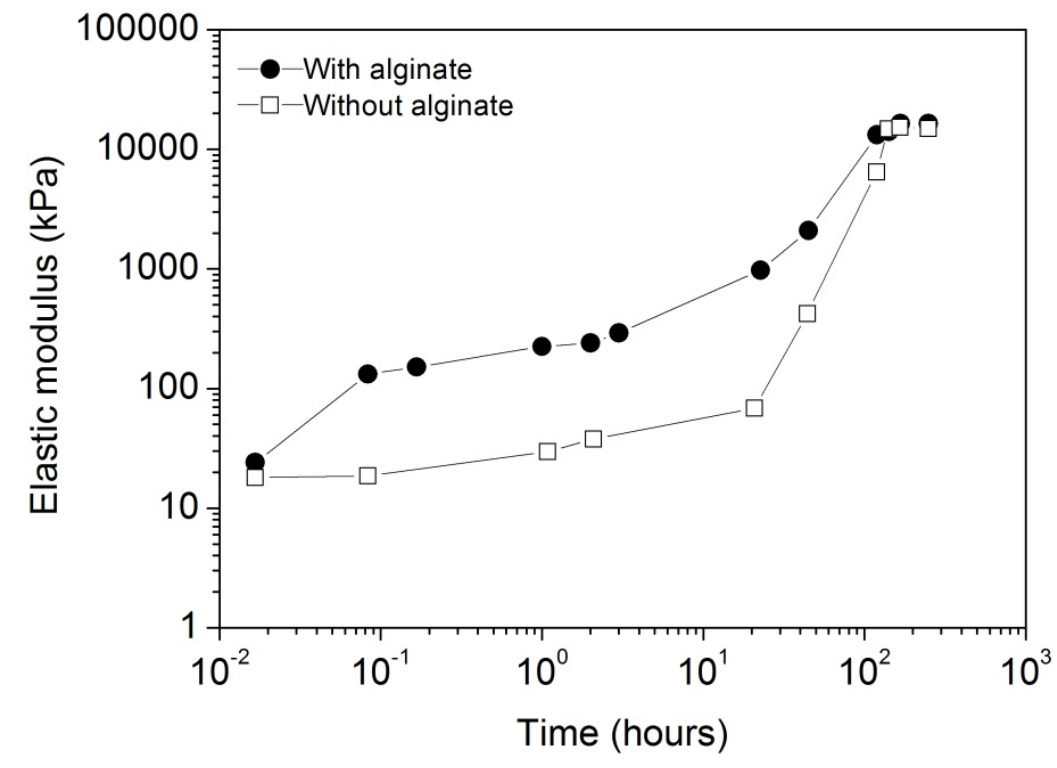

Figure 4: Evolution of the yield stress of the earth at rest with and without alginate.

\section{First prints and compressive strength of printed samples}

\section{IV.1 First prints}

Earth prints have been carried out for earth with and without alginate. The pressure recorded by the pump was equal to 12 bar in each case. The extruder velocity was adjusted to the flow 
rate and was equal to $2 \mathrm{~cm} / \mathrm{s}$. The time between each layer deposit was approximately equal to 60 seconds. The number of printed layers ranged between two to four as shown on Figure 2 and 4. Straight samples were printed on a $1.2 \times 1.2 \mathrm{~m}^{2}$ table (Figure 4). The layers were perfectly superimposed and no weakness between elementary layers or cylinders was visible.
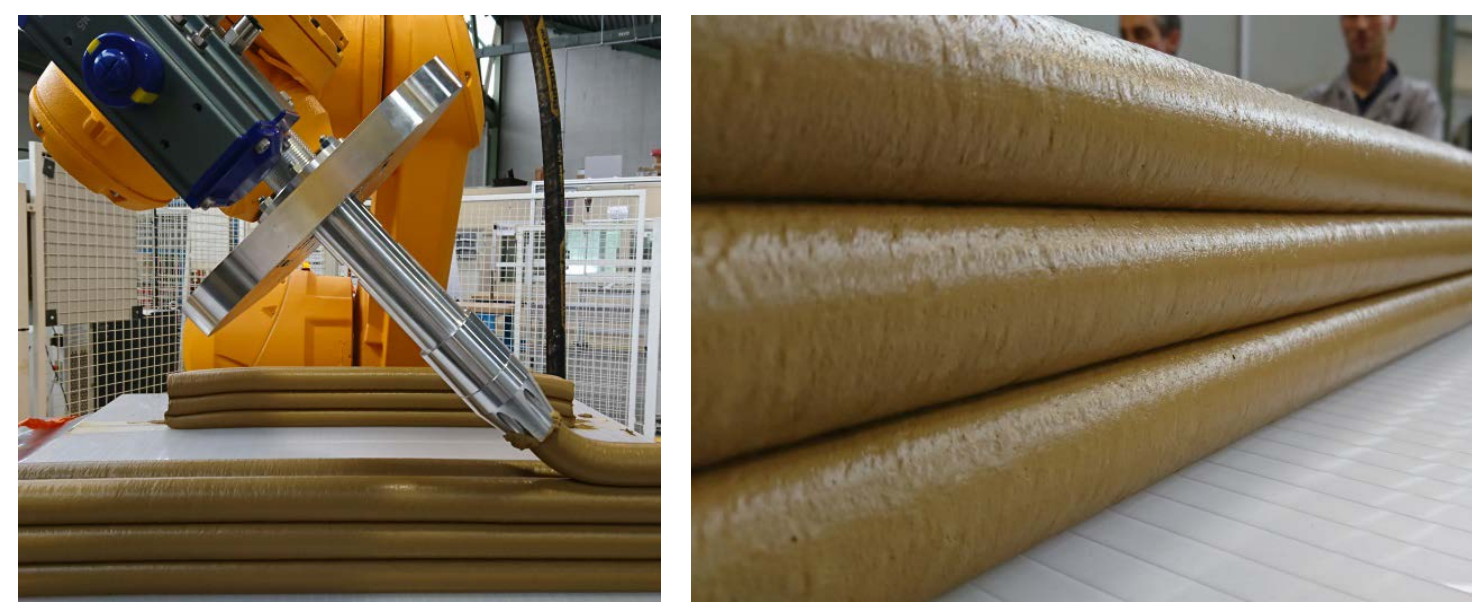

Figure 4: First performed earth printing.

IV.2 Mechanical performance of printed samples.

After samples were allowed to dry at $20^{\circ} \mathrm{C}, 50 \% \mathrm{RH}$ until samples weight stabilization, three layers high samples of a structure printed with circular die and four layers high samples of a structure printed with rectangular die, formed with and without alginate, were cut into $35 \mathrm{~mm}$ long samples for compressive strength measurements. The samples were directly tested with a load applied in the vertical direction (perpendicular to extruded layers) without surface preparation. The picture of the cut section of a sample with alginate is shown on Figure 5. 

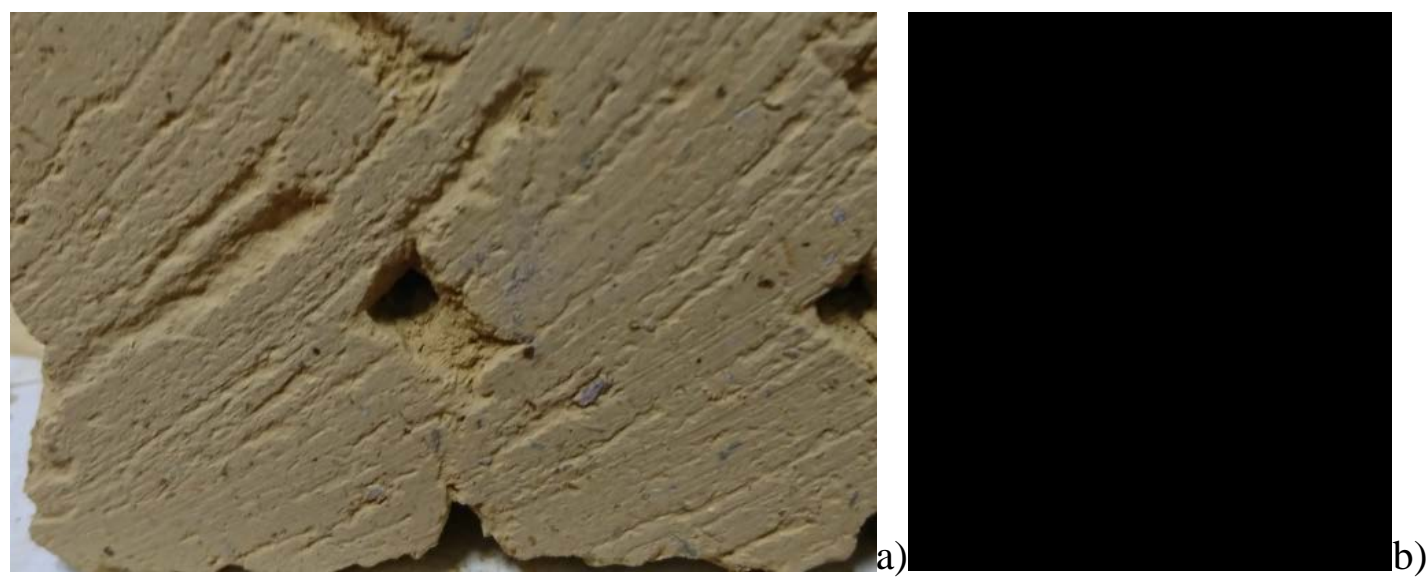

Figure 5: Cut section of printed samples of earth with alginate. a) printed with circular cross section - b) printed with rectangular cross section

In case of circular die, it can be observed that, due to the form of the extruder die and to the circular cross section of the extruded layers, some voids remain in the section. On contrary, for the rectangular extruder, we can observe a full section. In both case, it is also important to note the absence of cold joints between extruded layers and extruded rows. This means that the used time gap between each successive deposit was not too long and allowed a good adherence between layers.

Compressive tests measurements for samples printed with the circular cross section die, plotted in Figure 6, show that samples with and without alginate exhibit apparent compressive strength of about $1.2 \mathrm{MPa}(1.21 \pm 0.03$ for printed material with alginate and $1.22 \pm 0.04$ without alginate). Such a level of strength is in agreement with conventional cob earth material but could be improved with an improvement of the extruder die design and a reduction in the volume of voids within the printed samples. It is also important to note that the surface of the tested samples was not perfectly flat (due to the section of the printed layers) and leads to a measured values of strength lower than the strength of the plain material. 
This is in agreement with the results obtained with the samples printed with the rectangular cross section which exhibit higher compressive strength (Figure 7). Those samples with a plain section exhibits compressive strength of about $1.7 \mathrm{MPa}(1.77 \pm 0.03$ for printed material with alginate and $1.65 \pm 0.04$ without alginate)

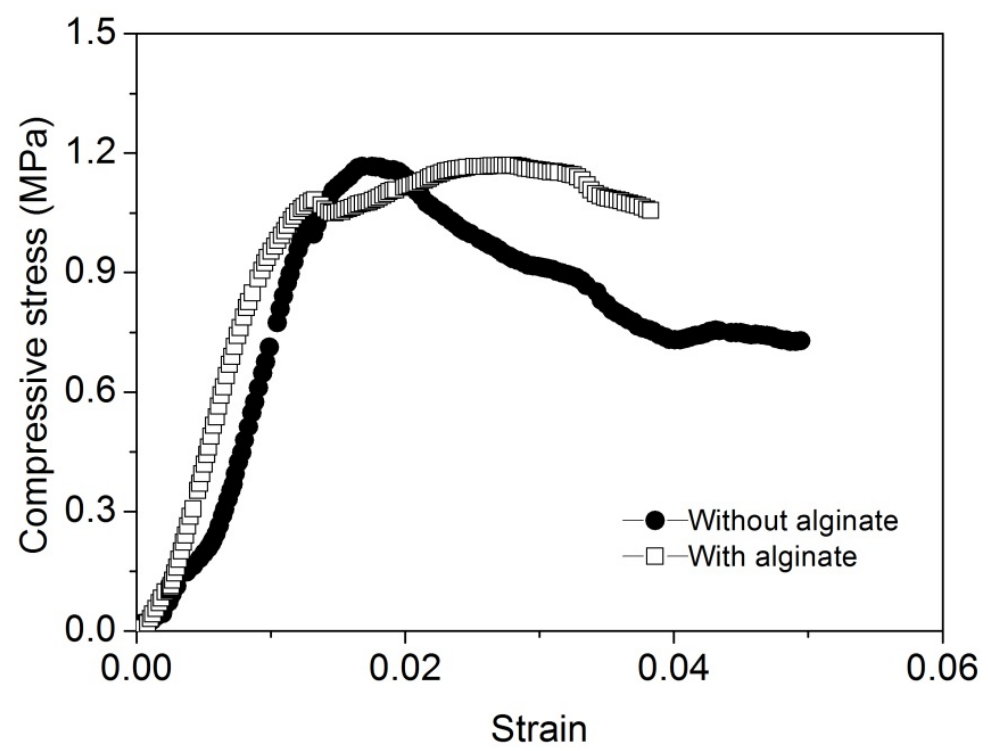

Figure 6: Compressive strength measurement curves for printed earth with and without alginate (circular cross section).

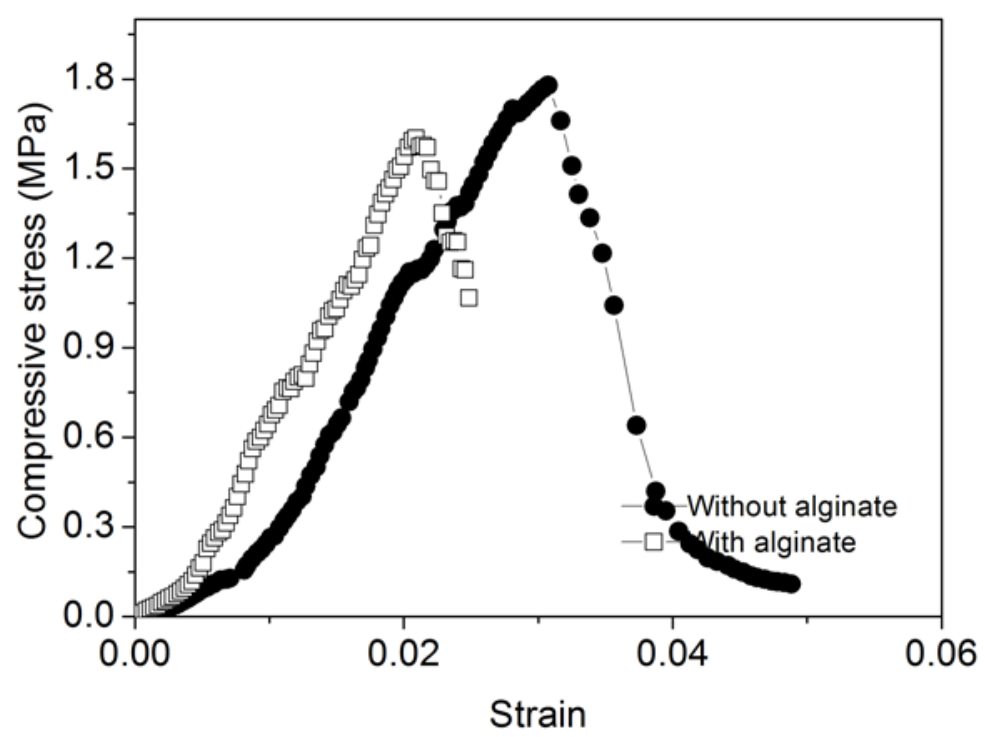


Figure 7: Compressive strength measurement curves for printed earth with and without alginate (rectangular cross section).

\section{Conclusions}

In this study, we have assessed the possibility of producing a printed structure with earthbased material. Based on studies on the feasibility of concrete 3D printing and with addition of alginate to the earth it was possible to achieve high productivity (for example, building a 3 metres wall in a working days); the alginate addition was used to improve green strength. It has been demonstrated that the benefit brought about by alginate addition in terms of fast increase in green strength which was quantified by penetrometry measurements.

A study of the first simple 3D prints was then carried out and the results show that it is possible to print samples having compressive strengths that are comparable to those found in conventional earth-based material such as cob construction.

This study on the processing feasibility of earth 3D printing opens the door for further studies on construction design as it enables using topological optimization tools, printed materials mix-design, printed material durability, economical optimization and environmental cost estimation.

\section{Compliance with Ethical Standards:}

Funding: This study was not funded.

Conflict of Interest: The authors declare that they have no conflict of interest.

\section{References}

1. Aubert JE, Maillard P, Morel JC, Al Rafii M (2015) Towards a simple compressive strength test for earth bricks? Mater Struct 1-14 . doi: 10.1617/s11527-015-0601-y 
2. Azeredo G, Morel J-C, Lamarque C-H (2008) Applicability of rheometers to characterizing earth mortar behavior. Part I: experimental device and validation. Mater Struct 41:1465-1472 . doi: 10.1617/s11527-007-9343-9

3. Bui Q-B, Morel J-C, Hans S, Meunier N (2009) Compression behaviour of non-industrial materials in civil engineering by three scale experiments: the case of rammed earth. Mater Struct 42:1101-1116 . doi: 10.1617/s11527-008-9446-y

4. Moevus M, Jorand Y, Olagnon C, et al (2015) Earthen construction: an increase of the mechanical strength by optimizing the dispersion of the binder phase. Mater Struct 1-14 . doi: 10.1617/s11527-015-0595-5

5. Gnanli L, Ouellet-Plamandon C, Brumaud C, Habert G (2014) Development of a SelfCompacted Clay based Concrete, rheological, mechanical and environmental investigations. Barcelona, Spain

6. Ouellet-Plamondon C, Landrou G, Palacios M (2015) Earth concrete as a promising building material

7. Landrou G, Brumaud C, Habert G (2017) Clay particles as binder for earth buildings materials: a fresh look into rheology of dense clay suspensions. In: EPJ Web of Conferences. EDP Sciences, p 13010

8. Landrou G, Brumaud C, Winnefeld F, et al (2016) Lime as an Anti-Plasticizer for SelfCompacting Clay Concrete. Materials 9:330

9. Dove CA, Bradley FF, Patwardhan SV (2016) Seaweed biopolymers as additives for unfired clay bricks. Mater Struct 49:4463-4482 . doi: 10.1617/s11527-016-0801-0

10. Galán-Marín C, Rivera-Gómez C, Petric J (2010) Clay-based composite stabilized with natural polymer and fibre. Constr Build Mater 24:1462-1468 . doi: 10.1016/j.conbuildmat.2010.01.008

11. Achenza M, Fenu L (2006) On Earth Stabilization with Natural Polymers for Earth Masonry Construction. Mater Struct 39:21-27 . doi: 10.1617/s11527-005-9000-0

12. Khelifi H, Lecompte T, Perrot A, Ausias G (2015) Mechanical enhancement of cementstabilized soil by flax fibre reinforcement and extrusion processing. Mater Struct 1-14

13. Khelifi H, Perrot A, Lecompte T, Ausias G (2013) Design of clay/cement mixtures for extruded building products. Mater Struct 46:999-1010 . doi: 10.1617/s11527-012-9949-4

14. Maskell D, Heath A, Walker P (2013) Laboratory scale testing of extruded earth masonry units. Mater Des 45:359-364

15. Ouellet-Plamondon CM, Habert G (2016) Self-Compacted Clay based Concrete (SCCC): proof-of-concept. J Clean Prod 117:160-168 . doi: 10.1016/j.jclepro.2015.12.048

16. Bruno AW, Gallipoli D, Perlot C, Mendes J (2017) Mechanical behaviour of hypercompacted earth for building construction. Mater Struct 50:160 . doi: 10.1617/s11527-017-1027-5 
17. Khoshnevis B (2004) Automated construction by contour crafting-related robotics and information technologies. Best ISARC 2002 13:5-19 . doi: 10.1016/j.autcon.2003.08.012

18. Khoshnevis B, Hwang D, Yao K-T, Yeh Z (2006) Mega-scale fabrication by contour crafting. Int J Ind Syst Eng 1:301-320

19. Le TT, Austin SA, Lim S, et al (2012) Mix design and fresh properties for highperformance printing concrete. Mater Struct 45:1221-1232 . doi: 10.1617/s11527-0129828-z

20. Lim S, Buswell RA, Le TT, et al (2012) Developments in construction-scale additive manufacturing processes. Autom Constr 21:262-268 . doi: 10.1016/j.autcon.2011.06.010

21. Perrot A, Rangeard D, Pierre A (2016) Structural built-up of cement-based materials used for 3D-printing extrusion techniques. Mater Struct 49:1213-1220 . doi: 10.1617/s11527015-0571-0

22. Lloret E, Shahab AR, Linus M, et al (2015) Complex concrete structures: Merging existing casting techniques with digital fabrication. Mater Ecol 60:40-49 . doi: 10.1016/j.cad.2014.02.011

23. Wangler T, Lloret E, Reiter L, et al (2016) Digital Concrete: Opportunities and Challenges. RILEM Tech Lett Vol 1 2016DO - 1021809rilemtechlett201616

24. Lowke D, Weger D, Henke K, et al 3D-Drucken von Betonbauteilen durch selektives Binden mit calciumsilikatbasierten Zementen-Erste Ergebnisse zu beton-technologischen und verfahrenstechnischen Einflüssen

25. Lecompte T, Perrot A (2017) Non-linear modeling of yield stress increase due to SCC structural build-up at rest. Cem Concr Res 92:92-97 . doi:

10.1016/j.cemconres.2016.11.020

26. Mettler LK, Wittel FK, Flatt RJ, Herrmann HJ (2016) Evolution of strength and failure of SCC during early hydration. Cem Concr Res 89:288-296 . doi: 10.1016/j.cemconres.2016.09.004

27. Lootens D, Jousset P, Martinie L, et al (2009) Yield stress during setting of cement pastes from penetration tests. Cem Concr Res 39:401-408 . doi:

http://dx.doi.org/10.1016/j.cemconres.2009.01.012

28. Roussel N (2006) A thixotropy model for fresh fluid concretes: Theory, validation and applications. Cem Concr Res 36:1797-1806 . doi:

http://dx.doi.org/10.1016/j.cemconres.2006.05.025

29. Leuven KU (2014) Additive manufacturing of ceramics: a review. J Ceram Sci Technol $5: 245-260$

30. Paoletti I (2017) Mass customization with additive manufacturing: new perspectives for multi performative building components in architecture. Procedia Eng 180:1150-1159

31. Mohammed JS (2016) Applications of 3D printing technologies in oceanography. Methods Oceanogr 17:97-117 
32. Peña del Olmo MN (2011) Additive manufacturing of non plastic porcelain material by direct writing and freeze casting.

33. Perrot A, Lecompte T, Estellé P, Amziane S (2013) Structural build-up of rigid fiber reinforced cement-based materials. Mater Struct 46:1561-1568

34. Perrot A, Rangeard D, Levigneur A (2016) Linking rheological and geotechnical properties of kaolinite materials for earthen construction, Materials and Structures/Materiaux et Constructions, 49: 4647-4655

35. Funami T, Fang Y, Noda S, et al (2009) Rheological properties of sodium alginate in an aqueous system during gelation in relation to supermolecular structures and Ca 2+ binding. Food Hydrocoll 23:1746-1755

36. Wolfs RJM, Bos FP, Salet TAM (2018) Early age mechanical behaviour of 3D printed concrete: Numerical modelling and experimental testing. Cem Concr Res 106:103-116 . doi: 10.1016/j.cemconres.2018.02.001 